\title{
Educating Multiples in the Classroom: Together or Separate?
}

\author{
Megan T. Alexander
}

Published online: 17 January 2012

(C) Springer Science+Business Media, LLC 2012

\begin{abstract}
The drastic increase in the birthrate of twins and multiples makes the education of these children an important issue for parents and educators. Many educators and parents disagree on whether it is better for these children to be educated in the same classroom or apart. After conducting research, one can analyze the feelings of parents and educators on the education of twins and multiples. In addition to research, additional interviews were also analyzed to assess the feelings of twins and multiples on being educated together or apart from one's siblings. The children interviewed offered the most insight into the implications involved in separating twins and multiples in the classroom versus keeping them in the same classroom. While both separation and keeping children together has its pros and cons, one can conclude that the children involved should have the most say in their own education. Twins and multiples themselves may be the best source of information when rendering a decision about whether or not to educate them in the same classroom.
\end{abstract}

Keywords Twins $\cdot$ Multiples $\cdot$ Education $\cdot$ Classroom

The use of fertility drugs has dramatically increased the rate of twins and multiple births in the United States. Between 1980 and 1994 alone, the birth rate of twins increased 42\% (Katz 1998). The incidence of multiple births has continued to increase since then with over four million twins, triplets, or other multiple sibling births being born each year (Types of twins 2009). The increase in multiple births is the result of not only fertility treatments, but also increased infant

M. T. Alexander $(\bowtie)$

456 Montgomery Drive, Westfield, IN 46074, USA

e-mail: megan.alexander89@gmail.com survival rates and women delaying pregnancies. With the incidence of multiple births on the rise, parents and educators are in debate over whether multiples should be kept in the same classroom or separated. Parents', educators' and children's opinions on this matter vary widely.

\section{Separation is Best for Multiples}

Many experts support the notion that separation is best for twins and other multiples. They believe that separation is the best way to help children develop their individuality, without being influenced by a sibling classmate (Blevins 2001). It is believed that multiples will become overly dependent upon each other if they are educated together from a young age. Schools and preschool programs tend to support this belief by having a fixed policy mandating the separation of twins and other multiples in the classroom (Katz 1998).

Separation also may decrease the likelihood twins or multiples will be compared with each other or given labels to differentiate between or among them. If, for example, a child is labeled as the "disruptive twin," he or she is more likely to continue to be disruptive. Parents and teachers may also emphasize differences between or among the children, such as physical, personality, or cognitive traits, in order to distinguish between them. Negative labels may adversely affect a child's self-esteem when he or she is perceived as inferior in some way to a sibling (Blevins 2001). Advocates of separate education for multiple siblings further contend that rivalry and competition between and among sibling peers can be decreased by separating children into different classrooms.

The perceptions of the children themselves also may be altered by assigning them to different classrooms. Many 
twins and multiples are perceived by parents, teachers, and others to be one unit or entity. This "collective identity" is reflected in practices such as dressing multiples alike or giving them similar sounding names. Multiples also tend to share interests and activities with their sibling peers. When this occurs, one child may become dominant while another becomes shy and unwilling to express his or her ideas (Beauchamp and Brooks 2003).

Overall, experts in support of separation indicate that there is no harm in separating twins and other multiples. If multiples are capable of forming friendships with nonsibling peers, then separation will not be an issue for them. For those children incapable of this, students should be separated daily, even if only for a short time, to help them develop socially (Katz 1998).

\section{Separation Hurts the Children}

In contrast to the opinions of many experts, $86 \%$ of twins' parents believe that their children should be kept together. Some teachers support parents in this idea because keeping twins and multiples together provides teachers with more opportunities to get to know the children and their family better (Beauchamp and Brooks 2003). Separation can also be detrimental to children since it may cause undue stress to the children and family involved. This is especially true if children are already facing excess stress within their family or health issues. The unnecessary stress can cause children to regress and cling to their sibling peers, instead of developing individuality (Blevins 2001).

Academically, socially and emotionally, there is some research to indicate that children actually do better when kept together than when separated. Children should be kept together because separation at a young age can lead to withdrawal, anxiousness, depression, and emotional distress, according to a University of Wisconsin and the Institute of Psychiatry at King's College in London, England (Tully et al. 2004).Twins and multiples help each other through both academic and social dilemmas by providing a support system in a new classroom setting.

In educating twins or multiples in the same classroom, teachers can still provide children with opportunities to develop their own personalities without being unduly influenced by sibling peers. One simple way that teachers can distinguish between and among multiple siblings is to consult with parents/families about physical differences that characterize each child, such as a birth mark. The likelihood that a child will be called by the twin's name, which causes stress on the children and teacher, is decreased (Katz 1998). In the classroom, teachers can also separate children into different groups to provide the students with opportunities to form friendships with other classmates. Teaming children up with non-siblings will also aid children in learning how they work with other children to assist them in developing leadership and individuality (Blevins 2001).

While keeping twins and multiples together is not widely supported by schools, school districts need to consider the specific situation. Keeping twins and multiples together provides a support system for children as they enter a new classroom environment or school; thus, if newly immigrated twins who are the only ones that speak a particular language in the school arrive, it may be wise to reconsider a general policy about separating twins into different classrooms. According to Katz (1998), twins and multiples are also no more disruptive in a classroom than non-siblings, leaving little reason not to allow them to be kept together. While keeping twins and multiples together is not damaging to the children involved, separation may be harmful to children because it sends a message that it is not acceptable for twins to work together (Blevins 2001). Separation also poses a greater risk for identical twins than fraternal twins, making same classroom education even more important for those children (Miller n.d.).

\section{Twins and Other Multiples' Perspectives}

While parents and schools have their own opinions on whether it is best for twins and multiples to be separated, children may have different perspectives on what is best for them. I conducted informal interviews with three twins, two triplets, and four quadruplets; I found that each child had his or her own opinion on whether or not siblings should be educated together or separately.

In talking with three individuals who are twins, none of the individuals were advocates of being educated alongside their twin sibling in the same classroom. Katrina Gerlach was one of the twins interviewed. She agreed with schools in that educating twins separately is more beneficial for the individual child. Katrina also felt that it can hurt siblings to place them in the same classroom if the children are not equivalent academically in all subject areas (K. Gerlach, personal communication, March 4, 2010). Another twin, Kristen Reif, said that despite being in different classrooms from her twin sister, she was still able to work with her sister on homework and study with her. Kristen felt that being able to work on the same material but not being in the same classroom was beneficial because it provided her and her sister with opportunities to work together while still being viewed as individuals in the classroom (K. Reif, personal communication, March 5, 2010). The third individual interviewed, Nathan Sinders, agreed with Katrina and Kristen in that it is difficult to be in the same classroom as a twin if academics were not equivalent. Nathan indicated that he and his twin sister often competed for better 
grades when they were in the same class. While this kept both twins on top of their school work, it left one of the twins being hurt in the end since one did not always do as well as the other. He also felt that being in the same class with his sister changed who he was as an individual; he could not be his usual "goof off" self, since his sister would tell his parents (N. Sinders, personal communication, April 10, 2010). Overall, the twins saw that the most benefits resulted from being educated in different classrooms on the same subjects. This allowed the twins to bond at home working together, yet allowing them to grow in their independence in school.

Two individuals who are triplets also offered insight onto the pros and cons of being educated in the same classroom as one's sibling peer. Megan Haigh was homeschooled with her triplet sister and brother up until fifth grade. She felt that being in the same classroom was therefore beneficial when she did enter school. The siblings could always rely on each other for help or team up to work on projects. However, as the individuals grew older, Megan saw more negatives to being in the same classroom as her siblings. She indicated that in classes which require a lot of discussion, it is better to not be in the same class as a sibling. Individuals are less concerned with what their siblings will think and more willing to speak up in class (M. Haigh, personal communication, March 4, 2010). Eilis Wasserman, also a triplet, agreed with Megan in some regards. She indicated that one major advantage to being in the same classroom with at least one of her brothers was that the siblings could share textbooks at home. The major disadvantage she saw was becoming annoyed with her siblings because they were constantly together at school and at home (E. Wasserman, personal communication, March 4, 2010). Overall, Megan and Eilis thought personality and relationships ought to be considered when deciding whether or not to educate multiples in the same classroom.

In a school with only two classrooms per grade, the Harton quadruplets, two boys and two girls, were always with at least one of their brothers or sisters each year of school, with the combinations switching yearly. While all four children were educated together, they now have differing views on the benefits and disadvantages of being in the same classroom. Steve, Claire, and Mary all believe that it was beneficial to be kept together with at least one of their siblings throughout school. Steve felt that being with his siblings was beneficial because they were not distracting in class. One could anticipate the behavior of a sibling, and therefore, could better focus in the classroom. He also felt that it was beneficial to have siblings in the same classroom to work on homework with and help outside of class (S. Harton, personal communication, March 6, 2010). Claire added that it was also fun to share a classroom with a sibling because homework time and study time could also easily be planned together (C. Harton, personal communication, March 7, 2010). Mary agreed (M. Harton, personal communication, March 7, 2010), but Ted suggested that while being educated together had its benefits, he also felt that there were advantages to being educated apart. He felt that with separation, each person had the opportunity to be seen more as an individual than a part of a unit (T. Harton, personal communication, March 7, 2010). While there were some differing opinions in the benefits of being kept together or separated, all four are now attending the same college. One can infer that since all four are at the same college and have chosen to take classes both together and apart, the siblings evidently recognize both advantages and disadvantages to being in the same classroom. By switching combinations of siblings together, the quadruplets were able to gain more independence than if the combinations were kept the same every year.

\section{What is Best for Children?}

After hearing the opinions of schools, parents, and children on whether it is best to educate children together or separately, one can conclude that this is not a question with one, right answer. There are pros and cons, both to keeping multiple siblings together in school and to assigning them to different teachers and classrooms. From an early childhood perspective, it does appear that keeping children together at a younger age can be beneficial; twins and other multiples benefit academically, socially, and emotionally from being kept together at a younger age (Tully et al. 2004). However, as siblings from the same birth process mature, these individuals frequently prefer to be separated from their siblings in order to decrease competition and promote independence. When considering the placement of twins and other multiples in the classroom, parents and educators need to consider what is best for the children. Children should also have the opportunity to offer their opinions about being in class together or in separate classrooms. Above all, decisions about whether to educate birth siblings in the same classroom or in different classroom settings should take the particular situation of the children and families into consideration.

\section{References}

Beauchamp, H., \& Brooks, L. (2003). The perceptions, policy, and practice of educating twins: A review. Psychology in the Schools, 40(4), 429-438.

Blevins, E. (2001, May/June). Classroom choice: Its your decision. Twins Magazine, Retrieved from http://www.twinsmagazine. com/schooldays/choices.shtml. 
Katz, L. (1998). Twins in school: What teachers should know. ERIC Digest, EDO-PS-98-10.

Miller, M. (n.d.). National organization of mothers of twins clubs, inc. School issues: separation or together? Retrieved from http://www. nomotc.org/index.php?option=com_content\&task=view\&id=157.

Tully, L., Moffitt, T., Caspi, A., Taylor, A., Kiernan, H., \& Andreou, P. (2004). What effect does classroom separation have on twins' behavior, progress at school, and reading abilities? Twin Research, 7(2). Retrieved from http://www.twinslaw.com/Twins_ Research_files/tully\%20report\%20merged\%20.pdf.

Types of twins. (2009, June 23). Retrieved from http://www.twin stuff.com/component/content/article/26-twin-facts/148-types-oftwins?directory $=27$. 